\title{
Performance Evaluation of Time Series Models using Short-Term Air Passenger Data
}

\author{
W. G. $\operatorname{Park}^{1} \cdot$ S. Kim ${ }^{2}$ \\ ${ }^{1}$ Digital Inclusion Policy Division Research fellow, NIA. \\ ${ }^{2}$ Department of Applied Statistics, Chung-Ang University
}

(Received November 7, 2012; Revised November 20, 2012; Accepted November 20, 2012)

\begin{abstract}
We perform a comparison of time series models that include seasonal ARIMA, Fractional ARIMA, and Holt-Winters models; in addition, we also consider hourly and daily air passenger data. The results of the performance evaluation of the models show that the Holt-Winters methods outperforms other models in terms of MAPE.
\end{abstract}

Keywords: ARIMA, FARIMA, Holt-Winters, air passengers.

\section{1. 서론}

최근 항공 수요 예측에 있어 시계열 모형의 도입이 활발하다. 그 중 항공 수요 예측뿐만이 아니라 수 요 예측에 있어 가장 대표적인 방법으로 Box와 Jenkins (1994)의 ARIMA 모형이 있으며, 장기 기억 모형 중 대표적인 수요예측 방법으로 Liu 등 (1999)이 FARIMA(Fractional Autoregressive Integrated Moving Average) 모형을 이용하여 수요 예측을 하였다. 항공 수요 예측에서는 Baik과 Kim (2008)은 제주-내륙 간 국내선 항공 수요 예측에 있어 선형 시계열 모형을 이용하였고, Hur 등 (2009)은 항공 수 요 예측을 위하여 일변량 시계열 모형인 계절형 ARIMA 모형과 다변량 시계열 모형인 벡터자기회귀 모형(vector autoregressive model; VAR)의 예측 성능을 비교하여 VAR모형의 성능의 우수성을 입증 하였다. Yoon 등 (2010)은 국제항공여객 및 화물의 수요예측을 위하여 계절형 일변량 시계열 모형과 계절형 다변량 시계열 모형을 비교하였으며, Son 등 (2012)은 ARIMA와 Holt-Winters, AR-GARCH 모형을 적용 후 이 예측 값들을 결합한 새로운 예측 값을 도출하여 예측 정확도를 비교하였다. Veloce (2004)는 $\mathrm{ECM}$ (error correction model)을 중심으로 ARIMA모형과 VAR모형과 지수평활법등과 예측 값을 비교하였고, Kulendran과 Wong (2005)는 계절성 단위근 검정의 결과와 계절형 ARIMA의 예측 결과를 비교하여 계절주기를 선택하였다. Gil-Alana (2005)는 장기 기억모형 중 대표적인 수요예측 방 법인 FARIMA(Fractional Autoregressive Integrated Moving Average) 모형을 사용하여 장기기억과 정의 입국자 예측 모형을 보여주었다. Shen 등 (2009)에 연구에서 계절형 ARIMA 모형과 구조모형 외

This research was supported by Basic Science Research Program through the National Research Foundation of Korea(NRF) funded by the Ministry of Education, Science and Technology (2012-220095).

${ }^{2}$ Corresponding author: Professor, Department of Applied Statistics, Chung-Ang University, 221 HeukseokDong, Dongjak-Gu, Seoul 156-756, Korea. E-mail: sahm@cau.ac.kr 
에 기타 계절형 모형을 비교하였다. 계절형은 그 주기가 하나로만 이루어 지지 않고 연별, 달별, 주일 별, 일별 주기가 복합적으로 이루어진다. 복합적인 계절형 수요예측은 항공 수요 예측 뿐만이 아리라 다른 분야에서도 활발히 연구되고 있다. Taylor (2003)는 전력수요예측 모형에서 수정된 이중 계절형 Holt-Winters 모형과 이중 계절형 ARIMA 모형을 통해 수요 예측 한 바 있으며, Taylor (2010)는 일별 과 주별, 연도별 주기를 이용한 삼중 계절형 지수평활법과 삼중 계절형 ARIMA 모형을 통해 예측을 하 였다. 본 연구의 주된 특징은 시간대별 입국자 자료를 이용하여 항공 수요 예측을 하고, 일별 입국자 자 료를 통한 분석과 예측 성능 비교를 통하여 시간대별 항공 수요 예측의 필요성을 보였다는 점이다. 아울 러 계절형 ARIMA, 계절형 FARIMA, Holt-Winters 모형과 수정 Holt-Winters모형의 예측 성능을 비 교하여, 수정 Holt-Winters모형의 예측 성능이 우수함을 보인다.

\section{2. 시계열 모형의 소개}

\section{1. 계절형 ARIMA(SARIMA) 모형}

계절형 시계열 모형에서 수요예측에 사용되는 대표적인 방법 중 하나는 Box와 Jenkins (1994)의 계절 형 자기회귀누적이동평균(Autoregressive Integrated Moving Average; ARIMA) 모형이다. ARIMA모 형은 다른 설명변수의 도입이 없어도 교란항과 과거치 만으로 시계열에 적합한 모형을 설정할 수 있도 록 하는 가장 기본적인 방법이으로, 단기예측과 계절형 변동을 포함하는 시계열의 분석에 효과적이다. Box의 이중 계절형 자기회귀누적이동평균의 기본 형태를 보면 (2.1)의 모형과 같다.

$$
\phi_{p}(B) \Phi_{P_{1}}\left(B^{s_{1}}\right) \Pi_{P_{2}}\left(B^{s_{2}}\right)(1-B)^{d}\left(1-B^{s_{1}}\right)^{D_{1}}\left(1-B^{s_{2}}\right)^{D_{2}} Z_{t}=\theta_{q}(B) \Theta_{Q_{1}}\left(B^{s_{1}}\right) \Psi_{Q_{2}}\left(B^{s_{2}}\right) \epsilon_{t},
$$

여기서 $B$ 는 $B^{k} Y_{t}=Y_{t-k}$ 에 연산을 맡는 후진연산자이고, $\phi_{p}(B)$ 와 $\theta_{q}(B)$ 는 $p$ 차 $\mathrm{AR}$ 과 $q$ 차 $\mathrm{MA}$ 를 의미한다. $\Phi_{P_{1}}\left(B^{s_{1}}\right), \Pi_{P_{2}}\left(B^{s_{2}}\right), \Theta_{Q_{1}}\left(B^{s_{1}}\right), \Psi_{Q_{2}}\left(B^{s_{2}}\right)$ 는 $s_{1}, s_{2}$ 에 따르는 $P_{1}, P_{2}, Q_{1}, Q_{2}$ 차 계절성 $\mathrm{AR}$ 과 계절성 $\mathrm{MA}$ 를 의미한다. $d, D_{1}, D_{2}$ 는 차분의 차수를 말하며, $\epsilon_{t}$ 는 백색잡음으로 $E\left(\epsilon_{t}\right)=0$ 이고 $\operatorname{Var}\left(\epsilon_{t}\right)=\sigma^{2}$ 이다. 다항식 $\phi_{p}(B)=0, \Phi_{P_{1}}\left(B^{s_{1}}\right)=0, \Pi_{P_{2}}\left(B^{s_{2}}\right)=0, \theta_{q}(B)=0, \Theta_{Q_{1}}\left(B^{s_{1}}\right)=0$, $\Psi_{Q_{2}}\left(B^{s_{2}}\right)=0$ 의 근은 단위원 밖에 위치한다.

\section{2. 계절형 FARIMA(Fractional ARIMA) 모형}

Fractional Seasonal ARIMA(FSARIMA)는 표준 Seasonal $\operatorname{ARIMA}(p, d, q)$ 모형의 일종으로서 $d$ 가 자연수가 아닌 실수를 가지는 모형이다. 이 모형은 장기기억특성을 반영한 모형이다. 이중 계절성 $\operatorname{FARIMA}$ 는 seasonal $\operatorname{ARIMA}(p, d, q)$ 에 대해 시계열 는 식 (2.2)와 같이 정의된다.

$$
\phi_{p}(B) \Phi_{P_{1}}\left(B^{s_{1}}\right) \Pi_{P_{2}}\left(B^{s_{2}}\right) \triangle^{d} Z_{t}=\theta_{q}(B) \Theta_{Q_{1}}\left(B^{s_{1}}\right) \Psi_{Q_{2}}\left(B^{s_{2}}\right) \epsilon_{t},
$$

여기서 $s_{1}, s_{2}$ 는 계절 성분의 주기이고, $\epsilon_{t}$ 는 평균 0 과 고정된 분산을 따르는 백색잡음과정이며 모형 의 정상성을 위해 $d \in(-0.5,0.5)$ 이며, $\triangle^{d}$ 는 분수차분 연산자(fractional differencing operator)로 식 (2.3)과 같이 정의된다.

$$
\triangle^{d}=(1-B)^{d}=\sum_{k=0}^{\infty}\left(\begin{array}{l}
d \\
k
\end{array}\right)(-B)^{k},
$$

여기서 $\left(\begin{array}{l}d \\ k\end{array}\right)=d ! /(d-k) ! k !$ 이다. 만약 $d=0$ 이면, FSARIMA 모형은 일반적인 SARIMA 모형이 된다. 


\subsection{Holt-Winters 모형}

Holt-Winters 지수평활법은 Holt의 이중 모수 지수평활법을 확장시킨 방법으로 계절형 시계열 예측에 사용되는 잘 알려진 방법이다. 지수 평활법은 계산이 쉽고 필요정보의 양이 최소화되는 장점이 있어 유 용하다. $Y_{t}$ 는 고려할 $t$ 시점의 전력수요량으로 계절주기를 $s$ 라고 하면 $L_{t}$ 는 $t$ 시점의 평활수준을 나타낸 다. $T_{t}$ 는 $t$ 시점의 평활가법추세를 의미하며, $S_{t}$ 는 $t$ 시점의 계절지표를 의미한다. $\alpha, \beta$ 는 수준과 추세에 대한 모수이고 $\gamma$ 는 계절평활 모수이며, $F_{t+h}$ 는 $h$ 시점 후에 예측한 값을 의미한다.

$$
\begin{aligned}
L_{t} & =\alpha\left(Y_{t}-S_{t-s}\right)+(1-\alpha)\left(L_{t-1}+T_{t-1}\right), \\
T_{t} & =\beta\left(L_{t}-L_{t-1}\right)+(1-\beta) T_{t-1}, \\
S_{t} & =\gamma\left(Y_{t}-L_{t}\right)+(1-\gamma) S_{t-s}, \\
F_{t+h} & =L_{t}+T_{t} \times h+S_{t+h-s} .
\end{aligned}
$$

이중 계절성을 적용시한 계절형 Holt-Winters 지수평활법은 식 (2.5)와 같이 적용된다. 여기서 $Y_{t}$ 는 고 려할 $t$ 시점의 전력수요량으로 계절주기를 $s_{1}$ 과 $s_{2}$ 라 하면 $L_{t}$ 는 $t$ 시점의 평활수준을 나타내며, $T_{t}$ 는 $t$ 시 점의 평활가법추세를 의미하며, $S_{t}$ 과 $D_{t}$ 는 $t$ 시점의 계절주기 $s_{1}$ 과 $s_{2}$ 의 계절지표를 의미한다.

$$
\begin{aligned}
L_{t} & =\alpha\left(Y_{t}-S_{t-s_{1}}-D_{t-s_{2}}\right)+(1-\alpha)\left(L_{t-1}+T_{t-1}\right), \\
T_{t} & =\beta\left(L_{t}-L_{t-1}\right)+(1-\beta) T_{t-1}, \\
S_{t} & =\gamma\left(Y_{t}-L_{t}-D_{t-s_{2}}\right)+(1-\gamma) S_{t-s_{1}}, \\
D_{t} & =\delta\left(Y_{t}-L_{t}-S_{t-s_{1}}\right)+(1-\delta) D_{t-s_{2}}, \\
F_{t+h} & =L_{t}+T_{t} \times h+S_{t+h-s_{1}}+D_{t+h-s_{2}} .
\end{aligned}
$$

식 (2.5)의 초기값은 식 (2.6)의 계산을 통하여 나타난다.

$$
\begin{aligned}
L_{s_{1}} & =\frac{1}{s_{1}} \sum_{t=1}^{s_{1}} Y_{t}, \\
L_{s_{2}} & =\frac{1}{s_{2}} \sum_{t=1}^{s_{2}} Y_{t}, \\
T_{s_{1}} & =\frac{1}{s_{1}^{2}}\left(\sum_{t=s_{1}+1}^{2 s_{1}} Y_{t}-\sum_{t=1}^{s_{1}} Y_{t}\right), \\
T_{s_{2}} & =\frac{1}{s_{2}^{2}}\left(\sum_{t=s_{2}+1}^{2 s_{2}} Y_{t}-\sum_{t=1}^{s_{2}} Y_{t}\right), \\
S_{1} & =Y_{1}-L_{s_{1}}, \ldots, S_{s_{1}}=Y_{s_{1}}-L_{s_{1}}, \\
D_{1} & =Y_{1}-L_{s_{2}}, \ldots, D_{s_{2}}=Y_{s_{2}}-L_{s_{2}} .
\end{aligned}
$$

평활 모수 $\alpha, \beta, \gamma, \delta$ 의 추정은 이 $m$ 개의 모형추정자료를 통하여 추정가능하다. 모형추정단계 중 1 차 시 점 예측에서 $\mathrm{SSE}$ (Sum of Squared Error)를 최소화하는 과정을 통하여 계산되며, $\mathrm{SSE}$ 는 식 (2.7)에 의 하여 계산된다.

$$
\mathrm{SSE}=\sum_{t=2}^{m}\left(Y_{t}-F_{t}\right)^{2}
$$




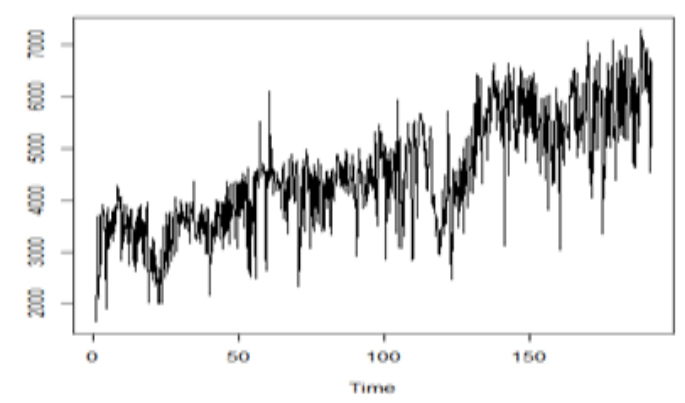

Figure 3.1. Time plot for daily data

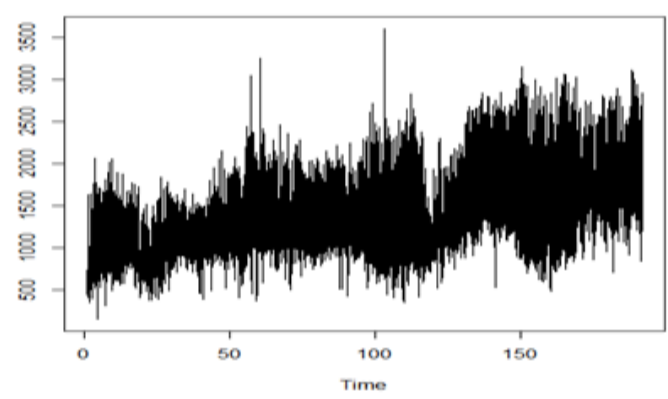

Figure 3.2. Time plot for hourly data

\section{4. 수정 Holt-Winters 모형}

수정 이중계절 Holt-winters 지수평활법은 Taylor (2003)에 의하여 제안되었다. 수정 Holt-Winters 지 수평활법은 식 (2.5)에서 $F_{t+h}$ 를 식 (2.8)과 같이 변형하여 정의한다.

$$
F_{t+h}=L_{t}+T_{t} \times h+S_{t+h-s_{1}}+D_{t+h-s_{2}}+\phi^{h}\left[Y_{t}-L_{t-1}-T_{t-1}-S_{t-s_{1}}-D_{t-s_{2}}\right],
$$

$\phi$ 는 1 차 상관계수에 조정을 나타내는 값으로 평활 모수 $\alpha, \beta, \gamma, \delta, \phi$ 는 1 차 예측단계에서 $\mathrm{SSE}(\mathrm{Sum}$ of Squared Error)를 최소화하는 과정을 통하여 계산된다.

\section{3. 실제 자료 분석}

분석에 이용된 자료는 2009 년 1월 1일 부터 2012 년 9 월 30 일까지의 한국공항공사를 통하여 얻은 입국 자수 자료이다. 현재 자료에는 인천공항을 통한 입국자수는 제외되어 있으며, 차후에 인천공항의 입국 자수가 확보될 경우 이를 포함시켜 분석을 할 것이 요구된다. 현재 자료는 일별자료와 시간대별 자료 로 2 종류의 자료가 있다. 시간대별 자료는 오전 6 시에서 정오까지와 정오에서 오후 6 시 까지, 오후 6 시 이후의 3 개의 시간대로 입국자 수를 나타낸 자료이다. 일자별 자료와 시간대별 자료는 각각 1369 개와 4107 개의 자료로, 1369 일의 입국자 수 자료이다. 2009년 1월 1일부터 2012년 8월 31일까지 1339 일 의 자료를 이용하여 모형을 적합 하는데 사용하였고, 2012년 9월 1일부터 2012년 9월 31일까지 30일 의 자료는 모형의 예측성능을 비교하는데 사용하였다. 일별자료에 대한 시계열 그림은 Figure 3.1로 나 타내었고, 시간대별 시계열 그림은 Figure 3.2와 같다. 모형 적합에 있어 계절형 ARIMA, FARIMA 모형은 AIC기준으로 판단하였으며, Holt-Winters 방법은 모수에 대하여 직접 추정하였다. 또한 정상 성을 만족시키기 위해 일자별 자료에서 계절형 ARIMA는 1 차 차분과 주별 주기인 7 차 차분을 하였 고, FARIMA에 경우 주별 주기인 7차 차분을 하였다. Holt-Winters는 원자료를 사용하였다. 시간대 별 자료에 대해서는 계절형 ARIMA에 대하여 일별주기인 3 차 차분과 주별 주기인 21 차 차분을 하였다, FARIMA는 주별 주기인 21차 차분에 대하여 사용하였고, Holt-Winters는 원자료를 사용하였다. 각 모 형에 대한 모수 추정 결과는 Table 3.1에서 Table 3.5와 같다.

추정된 결과 계절형 $\operatorname{ARIMA}$ 는 일자별 자료에서는 $\operatorname{ARIMA}(2,1,1)(0,1,1)_{7}$ 로 추정되며, 시간대별 자 료에서는 $\operatorname{ARIMA}(2,0,0)(1,1,1)_{3}(0,1,1)_{21}$ 로 추정되었다. FARIMA모형에 경우는 일별자료에 대하 여 차분치가 0.4529 인 $\operatorname{ARMA}(2,1)(0,1)_{7}$ 로 추정하였고, 시간대별 자료에 대하여는 차분치가 0.2758 인 $\operatorname{ARMA}(2,0)(2,3)_{3}(0,1)_{21}$ 로 추정하였다. Holt-Winters모형은 SSE를 최소로 하는 모수 값들을 추정 하였다. 각 모형의 예측 성능을 비교하기 위하여 (3.1)과 같은 MAPE(Mean Absolute Percentage Er- 
Table 3.1. Estimates of Seasonal ARIMA for daily data

\begin{tabular}{cccccc}
\hline 모수 & 추정값 & 표준오차 & 모수 & 추정값 & 표준오차 \\
\hline$\theta_{1}$ & 0.8706 & 0.0224 & $\phi_{1}$ & 0.4984 & 0.0346 \\
$\theta_{2}$ & 0.9091 & 0.0120 & $\phi_{2}$ & -0.0579 & 0.0312 \\
\hline
\end{tabular}

Table 3.2. Estimates of Seasonal ARIMA for hourly data

\begin{tabular}{cccccc}
\hline 모수 & 추정값 & 표준오차 & 모수 & 추정값 & 표준오차 \\
\hline$\Theta_{1(3)}$ & 0.8320 & 0.0117 & $\phi_{1}$ & 0.1639 & 0.0158 \\
$\Psi_{1(21)}$ & 0.8876 & 0.0074 & $\phi_{2}$ & 0.2490 & 0.0154 \\
& & & $\Phi_{1(3)}$ & 0.1866 & 0.0211 \\
\hline
\end{tabular}

Table 3.3. Estimates of Seasonal FARIMA for daily data

\begin{tabular}{cccccc}
\hline 모수 & 추정값 & 표준오차 & 모수 & 추정값 & 표준오차 \\
\hline$\theta_{1}$ & 0.5942 & 0.1666 & $\phi_{1}$ & 0.7373 & 0.1650 \\
$\Theta_{1(7)}$ & 0.9256 & 0.0105 & $\phi_{2}$ & -0.1672 & 0.0287 \\
\hline 추정된차분치 & $\hat{d}$ & 0.4529 & & & \\
\hline
\end{tabular}

Table 3.4. Estimates of Seasonal FARIMA for hourly data

\begin{tabular}{cccccc}
\hline 모수 & 추정값 & 표준오차 & 모수 & 추정값 & 표준오차 \\
\hline$\Theta_{1(3)}$ & -0.1850 & 0.1278 & $\phi_{1}$ & -0.1010 & 0.0159 \\
$\Theta_{2(3)}$ & 0.6784 & 0.0882 & $\phi_{2}$ & 0.1231 & 0.0158 \\
$\Theta_{3(3)}$ & 0.1442 & 0.0201 & $\Phi_{1(3)}$ & 0.1188 & 0.1280 \\
$\Psi_{1(21)}$ & 0.8860 & 0.0079 & $\Phi_{2(3)}$ & 0.7982 & 0.1206 \\
\hline 추정된차분치 & $\hat{d}$ & 0.2758 & & &
\end{tabular}

Table 3.5. Estimates of Seasonal Holt-Winters

\begin{tabular}{cccc}
\hline 모수 & 일별자료 & 시간대별자료 & 수정 Holt-Winters \\
\hline $\operatorname{LEVEL}(\alpha)$ & 0.562 & 0.2126 & 0.1779 \\
$\operatorname{TREND}(\beta)$ & 0.0049 & 0.0006 & 0.0007 \\
$\operatorname{SEASONAL} 1(\gamma)$ & 0.1968 & 0.1839 & 0.1816 \\
$\operatorname{SEASONAL2}(\delta)$ & - & 0.1202 & 0.1136 \\
$\phi$ & - & - & 0.0758 \\
\hline
\end{tabular}

ror)를 이용했다.

$$
\mathrm{MAPE}=\frac{1}{n-m} \sum_{t=m+1}^{n} \frac{\left|Y_{t}-F_{t}\right|}{Y_{t}} \times 100 \%
$$

여기서 $m$ 은 자료 적합에 사용한 표본 수, $n-m$ 은 예측에 사용된 표본 수이다. $Y_{t}$ 는 $t$ 시점에 실제 값 이고, $F_{t}$ 는 각 모형에 대한 예측 값이다. 제시한 모형과의 비교를 위하여 계절형 랜덤워크(RandomWalk; RW)모형을 사용한 결과 값을 제시했다. 계절형 랜덤워크 모형은 전주의 같은 요일의 수치를 예 측 값으로 사용하는 모형이다. 이러한 모형들의 MAPE는 Table 3.6, Table 3.7과 같다.

Table 3.6의 결과를 보면 우리가 제시한 모형 모두 참조모형보다 MAPE값이 작음으로 더 정확한 예 측을 하였다. 1 주간의 예측에서 시간대별 자료를 통한 수정된 Holt-Winters 모형을 이용한 예측이 가 장 좋은 수치를 보이며, $2,3,4$ 주간의 예측에서도 안정된 수치를 보인다. 수정되지 않은 Holt-Winters 
Table 3.6. MAPE for weekly forecast

\begin{tabular}{|c|c|c|c|c|c|c|c|c|}
\hline \multirow{2}{*}{ 기간 } & \multicolumn{3}{|c|}{ 일별자료 } & \multicolumn{4}{|c|}{ 시간대별 자료 } & \multirow{2}{*}{$\begin{array}{c}\text { 참조모형 } \\
\text { Seasonal-RW }\end{array}$} \\
\hline & HW & ARIMA & FARIMA & HW & ARIMA & FARIMA & adj-HW & \\
\hline 1주 & 3.387 & 8.315 & 4.348 & 3.278 & 7.152 & 5.447 & 3.073 & 12.691 \\
\hline 2 주 & 5.145 & 6.175 & 4.993 & 5.404 & 5.357 & 5.387 & 5.072 & 9.176 \\
\hline 3 주 & 5.712 & 8.985 & 6.080 & 5.737 & 7.509 & 6.331 & 5.661 & 10.609 \\
\hline 4주 & 6.912 & 11.360 & 7.147 & 6.951 & 9.515 & 7.295 & 6.949 & 10.842 \\
\hline
\end{tabular}

Table 3.7. MAPE for the 10-DAY post-sample period

\begin{tabular}{|c|c|c|c|c|c|c|c|c|}
\hline \multirow{2}{*}{ 기간 } & \multicolumn{3}{|c|}{ 일별자료 } & \multicolumn{4}{|c|}{ 시간대별 자료 } & \multirow{2}{*}{$\begin{array}{c}\text { 참조모형 } \\
\text { Seasonal-RW }\end{array}$} \\
\hline & HW & ARIMA & FARIMA & HW & ARIMA & FARIMA & adj-HW & \\
\hline 1일 & 3.312 & 5.854 & 3.758 & 1.644 & 5.393 & 5.231 & 2.259 & 5.202 \\
\hline 2 일 & 2.400 & 5.762 & 2.844 & 1.338 & 5.114 & 4.779 & 1.254 & 8.839 \\
\hline 3 일 & 1.807 & 7.005 & 3.058 & 1.815 & 5.996 & 4.525 & 1.447 & 9.475 \\
\hline 4일 & 1.973 & 7.509 & 2.751 & 2.197 & 6.185 & 4.269 & 1.741 & 10.161 \\
\hline 5 일 & 2.659 & 8.953 & 3.630 & 2.479 & 7.401 & 5.021 & 2.283 & 13.945 \\
\hline 6 일 & 2.352 & 9.235 & 3.561 & 2.124 & 7.536 & 4.987 & 1.942 & 13.076 \\
\hline 7 일 & 3.387 & 8.315 & 4.348 & 3.278 & 7.152 & 5.447 & 3.073 & 12.691 \\
\hline 8일 & 3.409 & 8.598 & 4.216 & 3.175 & 7.284 & 5.353 & 3.065 & 11.137 \\
\hline 9 일 & 3.137 & 8.241 & 3.923 & 3.143 & 6.822 & 4.829 & 2.963 & 10.166 \\
\hline 10일 & 3.453 & 7.879 & 3.874 & 3.610 & 6.342 & 4.617 & 3.363 & 9.719 \\
\hline
\end{tabular}

모형들도 역시 1 주간의 단기예측에서 타 모형들에 비하여 정확한 예측을 했다. FARIMA를 제외한 모 형들은 일별자료보다 시간대별 자료를 이용한 예측이 더 정확했다. FARIMA에 경우는 장기예측에 적 합한 모형으로 단기 예측에서는 적합하지 않은 것으로 사료된다. Table 3.6의 결과에서 FARIMA모형 을 제외하고시간대별 자료를 통한 예측이 각 모형에서 더 정확한 예측을 함이 나타난다. 특히 HoltWinters 모형은 다른 모형들에 비하여 더 낮은 MAPE값을 가짐을 알 수 있다. 이 중에서 1 일을 제외한 기간에서 모두 수정된 Holt-Winters 모형이 가장 예측정확도가 높았다.

\section{4. 결론}

일반적으로 항공여객 자료는 계절 성분이 존재하는 것으로 알려져 있다. 본 연구에서는 계절 성분 을 설명할 수 있는 계절형 ARIMA 모형, 장기예측에 적합한 FARIMA 모형, 지수 평할법을 확장 시킨 Holt-Winters 모형과 1차 상관관계를 적용한 수정된 Holt-Winters 모형을 이용하여 실제 자료 에 적합해 보았다. 그 결과 수정된 Holt-Winters 모형이 단기예측에서 가장 우수하였으며, 수정되 지 않은 Holt-Winters 모형들 또한 우수하였다. 일자별 자료와 시간대별 자료를 통한 분석의 비교 에서는 FARIMA를 제외하고 단기예측에서 시간대 별 자료를 통한 분석이 더 나은 결과가 나타났다. FARIMA는 일자별 자료를 통한 예측에서 우수한 성능을 보였는데, 이는 장기예측에 적합한 모형이기 때문인 것으로 사료된다. FARIMA에 경우는 장기 미래 예측으로 갈수록 안정적인 예측을 하는 것으로 나타난다. 이에 따라서 단기적으로는 시간별 자료를 통한 Holt-Winters 모형을 통한 예측과 장기적으 로 FARIMA를 통한 일별 예측을 병행하는 것이 필요하다. 본 논문에서는 인천공항에서의 입국자 자료 를 얻지 못하였기에 인천공항을 제외한 입국자수를 이용하여 나타내었으나, 향후에 이러한 자료를 보완 하여 모형을 고려해 볼 것이다. 또한 좀 더 다양한 자료와 자료의 계절성과 특성을 고려한 모형의 성능 평가를 시행하여 예측의 정확도와 신뢰도를 높이고자 한다. 


\section{References}

Baik, SeungHan. and Kim,Sungsoo. (2008). Estimation of air travel demand models and elasticities for Jeju-Mainland domestic routes, Korean Society of Transportation, 26, 51-63.

Box, G. E. P. and Jenkins, G. M. (1994). Time Series Analysis: Forecasting and Control, Prentice Hall.

Gil-Alana, L. A. (2005). Modelling international monthly arrivals using seasonal univariate long-memory processes, Tourism Management, 26, 867-878.

Hur, N.-K., Jung, J.-Y. and Kim, S. (2009). A study on air demand forecasting using multivariate time series models, The Korean Journal of Applied Statistics, 22, 1007-1017.

Kulendran, N. and Wong, K. K. F. (2005). Modeling seasonality in tourism forecasting, Journal of Travel Research, 44, 163-170.

Liu, J., Shu, Y., Zhang, L. and Xue, F. (1999). Traffic modeling based on FARIMA models, IEEE Canadian Conference on Electrical and Computer Engineering, 162-167.

Shen, S., Li, G. and Song, H. (2009). Effect of seasonality treatment on the forecasting performance of tourism demand models, Tourism Economics, 15, 693-708.

Son, H. G., Ha, M. H. and Kim, S. (2012). A study on the tourism combining demand forecasting models for the tourism in Korea, The Korean Journal of Applied Statistics, 25, 251-259.

Taylor, J. W. (2003). Short-term electricity demand forecasting using double seasonal exponential smoothing, Journal of Operational Research Society, 54, 799-805.

Taylor, J. W. (2010). Triple seasonal methods for short-term electricity demand forecasting, European Journal of Operational Research, 204, 139-152.

Veloce, W. (2004). Forecasting inbound Canadian tourism: An evaluation of error corrections model forecasts, Tourism Economics, 10, 263-280.

Yoon, J. S., Huh, N. K., Kim, S. and Hur, H. Y. (2010). A study on international passenger and freight forecasting using the seasonal multivariate time series models, Communications of the Korean Statistical Society, 17, 473-481. 